are carried over the shoulders; these join it in the middle line behind, while in front they bifurcate above the breasts, one strap passing to the corresponding busk, the other to the side of the corselet in relation to the anterior fold of the axilla where it supports the axillary expansion of the breast. Each corselet must be made for and fitted upon the individual wearer. In my opinion this is the best system of treating the malady under coneideration, but some women will not allow it in any circumstances, not because they are uncomfortable or are not relieved-they admit they are. Fashion steps in and abjures it. It seems that altering the type of stays often necessitates remaking the whole of the lady's outfit. For such cases I advise the second type, namely :

2. Corsets which are made so high that the breast cannot be impaled on any of their bones or steels whatever position the woman may assume. These corsets also require a pad to prevent undue pressure at the top of the front fastening. My objection to these corsets is that the breasts fall into V-shaped cavities and are more or lees pinched between the corsets and the chest wall as well as being pushed apwards and towards each other. Further, the nipples are pressed either upwards or backwards, and I cannot suggest any means of protecting them which women will wear. I believe it to be important to protect the nipples as much as possible, considering their important nervous, vascular, and lymphatic relations.

Dangerous corsets, and those which cause most of the trouble, are neither too high nor too low to prevent the breasts from being impaled upon their bones or steels when the wearers bend forwards or laterally. Sach corsets look perfectly harmless when the patient is standing and sitting, bat directly the body is bent either forwards or laterally the steels and bones can be seen to dig into the breast, as in Figs. $1_{A}, 2_{A}, 3_{A}, 4_{A}$. Tery often a patient will come to consult a surgeon in new corsets which do not appear to be in any way connected with the changes in the breasts; but when he sees those which were in constant use, the cause and effects are often very obvious.

I would draw your attention to the relation between chronic irritation and cancer. In this connexion I have repertedly seen cases in which the position of cancer in the breast corresponded exactly to the site of bone pressure of the stays (see Figs. $1_{A}, 2 A, 3 A, 4 A$, which are reproduced from the actual cases of cancer of the breast seen in Figs. 1, 2, 3, 4 respectively). Were inquiry to stop here, one would imagine a strong case had been proved, and that a definite relation existed between the constant irri tation from bone pressure of stays and cancer of the breast. But on investigating the matter further, I must say that $I$ have also seen cases of cancer of the breast in which the corsets worn could not be definitely anatomically assosiated with the disease; for I have seen people with severe corset pressure on the lower parts of the breasts, but cancer appeared in the upper parte, where no pressure of the kind existed; and I have had patients suffering from cancer of the breast who had never worn corsets a all, and in many of these cases the cancers were situated exactly where injurious bone pressure would have been expected, that is, in the lower and outer margins of the glands. Lastly, although I have shown you cases where cancer has appeared exactly on the parts where staybones have pressed habitually, I have never seen a case of chronic traumatic mastitis from this cause develop into cancer; and it is rare to see a case of cancer in a breast which is also suffering from chronic mastitis from any cause. I do not believe that a breast suffering from chronic mastitis is very likely to be the seat of a cencer. The relation is by no means so close as that which exists between chronic superficial glossitis and squamous epithelioma, or between leucoplakia around the vulva or anus and squamous epithelioma. Hence I am not justified in assuming that because cancer appears in most cases where direct local irritation is applied, this direct local irritation is the cause. At the same time one must realize that it is very common to find staybones impaling a breast at the point where cancer exists, as seen in Cases $1,2,3$ and 4, which are only examples of a long series of cases. Still, the relation between cancer of the breast and corset irritation cannot stand merely on the fact that the same area of the breast is affected by the two conditions. It must stand upon the evidence afforded elsewhere of a definite relation between chronic irritation and cancer, a subject wbich I have discussed in an article entitled Biotripsis, or Lifewear, in the British Medical Jodras, June 12th, 1909. Ample reasons exist for insisting that patients should never wear anything that can act as a constant source of irritation, especially to epithelial tissue, subject to such varying activity as that of the mammary gland.

\section{an UNUSUal fORm of perineal hernia.}

$$
\begin{aligned}
& \text { A. G. ATKINSON, B.A.Cantab., M.R.C.S., L.R.C.P., } \\
& \text { UPPER Nonwood. }
\end{aligned}
$$

THE following case of hernia appears to be one of sufficient interest and rarity to be placed on record. The patient was a fairly well nourished premature (8 months) female child, aged 3 weeks. Nothing had been noticed to be wrong with the child until the morning on which she was admitted to the General Infirmary, Salisbury. That morning it was found that there was a large bleeding mass in the valva:

State on Admission.

When taken into the hospital a few hours later, an in tensely congested pyriform swelling, bleeding resdily when touched, was found Jying between the labia. It measured about $1 \frac{1}{2}$ in. in length, and $i$ in. in diameter, narrowing at its attached end to a thick, short pedicle. The mass projected backwards, covering the vaginal orifice and anus. On turning it forwards, the vagina was found to be unobstructed, and the pedicle was seen emerging from the urethral orifice. A probe passed readily along the urethra, anterior to the pedicle, but could not be swept round it posteriorly. The probe passed into the bladder for a distance of about 2 in. No reduction was possible, and one could not determine whether any gut was present in the sac.

\section{Operation.}

The child was operated upon the same evening, and the mass was found to be a thick-walled congested sac, containing a litt] fluid only. A probe passed readily into the general peritoneal cavity. The sac was removed after ligature of its neck. The stump retracted into the urethra, leaving the external parts quite normal in appearance. There was no difficulty in micturition after the operation, and recovery was aninterrupted.

\section{Histology.}

Histological examination showed an outer layer of stratified epithelium derived either from bladder or urethra. There was an endothelial lining, presumably peritoneal, a layer of smooth muscular fibres and connective tissue intervening.

There seems little doubt that the hernia was con. genital ; whether it had been unnoticed by the nurse until the bleeding from abrasion of the congested macous mem. brane, and increase in size from partial strangulation made it obvious, or whether it was recently extruded from the meatue, I am unable to decide. The abraded condition of the mucous membrane covering it pointed to the first alternative rather than the second. As there was no difficulty with mictarition either before or after operation, one would conclude that the urethra only was involved, and not the trigone or base of the bladder.

The hernia would seem to have arisen from an abnormally deep vesico-uterine pouch, passing down between the urethra and vagina. From this the sac passed forward through the posterior wall of the urethra, being then extruded through the urinary meatus. I have been unable to find any record of a similar case. Macready (4 Treatise on Ruptures, 1893), discussing 40 recorded cases of perineal hernia, does not inclade this form, but quotes a case in which the sac appears to have come down between the bladder and vagina, bulging into both cavities.

I am indebted to Mr. H. L. E. Wilks, who operated upon the child, for permission to record the case.

DURING the current winter semester (1910.11) the number of medical students in the several universities of Switzerland is as follows: Basle, 183 (175 men, 8 women); Berne, 351 (190 men, 161 women) ; Geneva, 584 (289 men, 295 women) ; Lausanne, 299 (173 men, 126 women) ; Zurich, 432 (272 men, 160 women); total, 1,849 (1,099 men, 750 women). Of the whole number, 655 are Swiss, and of these 45 are women. 